\title{
ResearchOnline@JCU
}

This is the Accepted Version of a paper published in the Book McGraw-Hill Yearbook of Science and Technology 2010:

Wurster, Christopher, Bird, Michael, and Mcfarlane, Donald (2010) Bat guano: record of climate change. In: McGraw-Hill Yearbook of Science \& Technology 2010. McGraw-Hill Yearbook of Science \& Technology . McGraw-Hill, New York, NY, USA, pp. 34-36. 
McGraw-Hill 2010 YearBook of Science \& Technology

Galley Proofs

Keystroked: 14/05/2009

Initial MS Page Sequence Stamp: 00000

Article Title: Bat guano: Record of climate change

Article ID: YB100123

1st Classification Number: 553000

2nd Classification Number: 555000

Sequence Number:

\section{Bat guano: Record of climate change}

Bats are a ubiquitous group of flying mammals found on every continent except Antarctica, with highest abundance and diversity in the tropics and subtropics. Some species are very gregarious and may roost together in caves in substantial numbers. For example, the Mexican free-tailed bat may roost in maternity colonies reaching in excess of 20 million individuals in the semiarid parts of northern Mexico and the southwestern United States. These high population densities can result in bleached fur on the bats as a result of the high concentration of ammonia given off by microbial processing of bat urine and excrement (guano). Smaller populations of bats produce considerable quantities of guano, which, over thousands of years, can lead to deposits many meters thick on the cave floor. Sizable guano deposits have been mined for fertilizer, with the remaining deposits now serving as valuable archives of past environmental change.

Any sediment that accumulates over time has the potential to unlock secrets of the past, and bat guano is no exception. Guano contains several environmental proxy indicators and can also be reliably datedtwo key requirements for deciphering a record of past climate change. Bat guano, like all organic matter, is composed mostly of the elements carbon, nitrogen, hydrogen, and oxygen. The relative abundance (ratio) of each element's stable isotopes in a sample of guano is related ultimately to the local climate at the time the guano was produced. The stable isotopic composition of bat guano can be precisely measured by isotope-ratio mass spectrometry, and from these data the environment at the time of guano production can be deduced. In a stableisotope ecology, the general rule is that "you are what you eat." For insectivorous bats, this means the isotope ratios of the guano are approximately the same as the average stable isotope composition of the insects the bats consumed. Most gregarious caverniculous bats are nonselective in their feeding behavior, sampling insects around their roost. The insects are then processed in the gut of the bats, and the exoskeletons, along with metabolic wastes, are dropped onto the cave floor together with the fecal material of thousands of other bats. By sampling material down through a bat guano deposit, we can measure the changing isotope ratios of carbon, nitrogen, hydrogen, and oxygen of insects in the past. But what do these isotopic ratios mean?

Stable isotopes of guano. Stable carbon isotope ratios of plants $\left(\delta^{13} \mathrm{C}\right)$ are related primarily to the photosynthetic pathway used to convert carbon dioxide to organic carbon. There are three major pathways: $\mathrm{C}_{3}$ (Calvin), $\mathrm{C}_{4}$ (Hatch-Slack), and CAM (Crassulacean acid metabolism). Because each pathway uses a different set of chemical reactions to transport carbon, large differences in carbon isotope ratios occur between $\mathrm{C}_{3}$ plants and $\mathrm{C}_{4}$ plants. $\mathrm{Be}$ cause $\mathrm{C}_{3}$ plants (trees and cool-climate grasses) dominate in forests and temperate regions and $\mathrm{C}_{4}$ plants (tropical grasses) dominate in hot arid and semiarid 


\section{Bat guano: Record of climate change}

environments, the carbon isotope composition of plant material can be related to the environment in which the plant grew. In more arid climates, where CAM plants such as cacti and agaves may be locally abundant, stable carbon isotope ratios are similar to $\mathrm{C}_{4}$ plant ratios. Thus, the stable carbon isotopic composition of insects feeding on the plants, and ultimately the guano of bats feeding on the insects, represents an integrated measure of the carbon isotope composition of the vegetation. The carbon isotope composition of bat guano is lower in $\mathrm{C}_{3}$-dominated ecosystems and higher in $\mathrm{C}_{4}$ - and/or CAM-dominated ecosystems, and the distribution of these plant types is strongly correlated with climate.

Interpreting variations in nitrogen isotope ratios $\left(\delta^{15} \mathrm{~N}\right)$ in bat guano is more problematic. In the southern United States, there was no relationship between fresh guano $\delta^{15} \mathrm{~N}$ values and obvious climate indices, suggesting that local soil $\delta^{15} \mathrm{~N}$ values may be most important in determining guano $\delta^{15} \mathrm{~N}$ value. As guano degrades, ammonia is given off and the residual nitrogen is locked in unique guano minerals that have relatively high nitrogen isotope values compared with the original guano, obscuring the original isotope signal.

Stable isotope values of hydrogen $(\delta \mathrm{D})$ and oxygen $\left(\delta^{18} \mathrm{O}\right)$ in bat guano are ultimately related to local precipitation, and the processes controlling isotope ratios of water are well known. Seasonal changes and latitudinal variation in insolation patterns drive precipitation and evaporation. As energy and moisture is distributed from the tropics to the poles, changes in the isotopic composition of both hydrogen and oxygen occur. Cooler temperatures at higher latitudes and higher altitudes cause rain to condense with higher $\delta^{18} \mathrm{O}$ and $\delta \mathrm{D}$ values compared with the isotopic composition of the remaining water vapor. As water vapor moves to higher latitudes and higher altitudes, $\delta^{18} \mathrm{O}$ and $\delta \mathrm{D}$ values decrease. This means that as one moves to higher latitudes or higher altitudes with lower average temperatures, $\delta^{18} \mathrm{O}$ and $\delta \mathrm{D}$ values of precipitation decrease. This also means that winter precipitation has a more negative isotope composition than summer precipitation, and that tropical storms and cyclones are also depleted in the heavy isotopes of water. (In the tropics, the more it rains, the lower are the $\delta \mathrm{D}$ and $\delta^{18} \mathrm{O}$ values.) These patterns are further modified by variations in moisture source, humidity, seasonality of precipitation, and storm-track patterns.

Paleorecords. We have so far discussed the relationship between the isotope composition of contemporary guano and climate. However, it is possible that the isotope ratios of guano can change after deposition as a result of decomposition by fungi and bacteria, and mineral material in the deposits can also contain hydrogen and oxygen. These problems can be overcome by extracting the originally deposited, intact insect cuticles (exoskeletons) from the bulk guano sediment (Fig. 1). Comparisons of carbon isotope values of these extracted remains with bulk guano sediment values indicate that similar profiles are obtained, suggesting little postmodifica- 


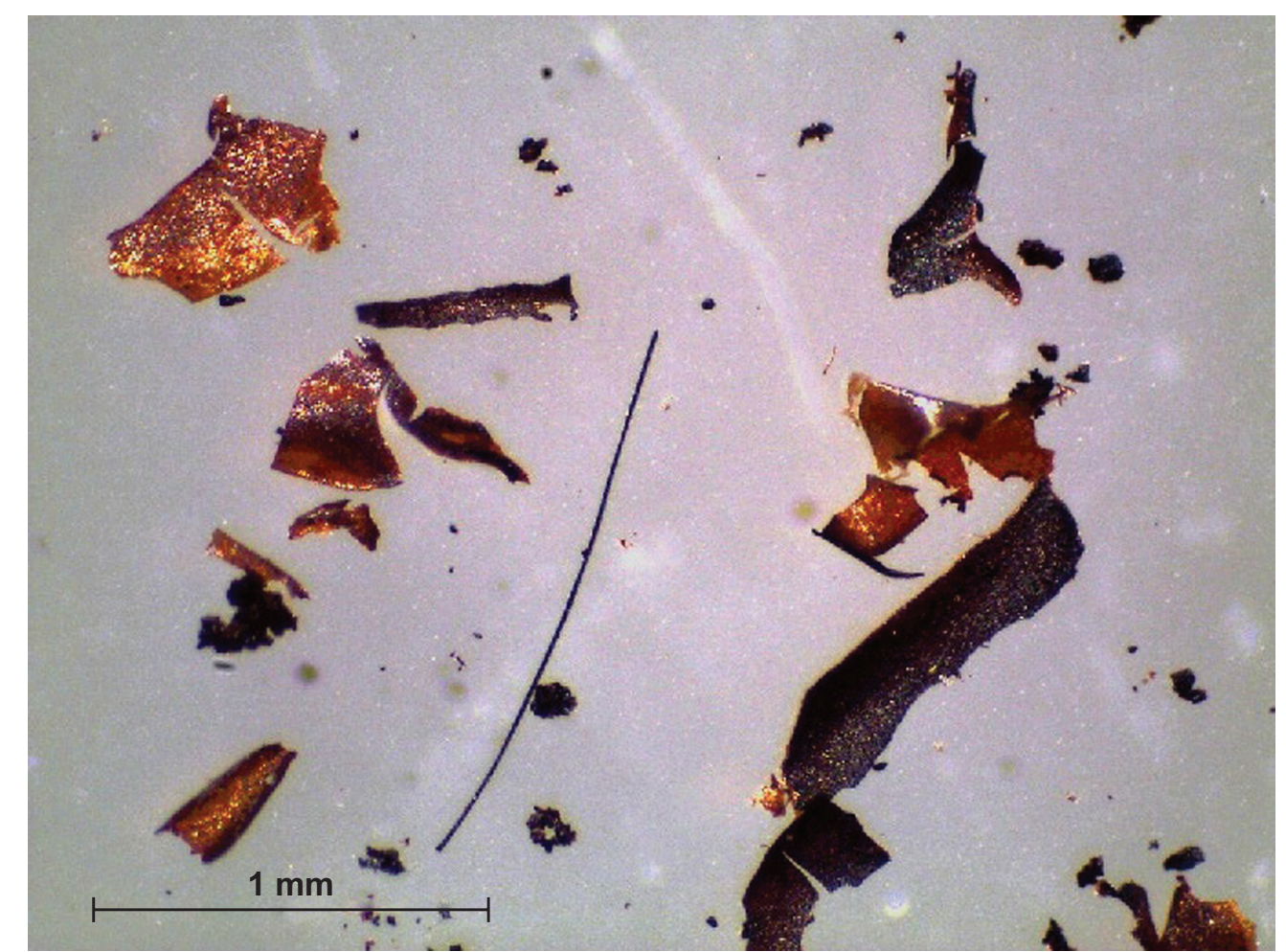

Fig. 1. Insect cuticles recovered from bat guano sediment. $\delta^{13} \mathrm{C}$ values from this sample indicate that there was an open savannah environment in Peninsular Malaysia about 25,000 years ago.

tion of carbon. Because of contamination and diagenesis, the nitrogen, oxygen, and hydrogen isotope composition of the bulk guano is very different from the composition of the insect cuticles. This suggests that although carbon isotopes in bulk guano can be used reliably to infer past climate, it is preferable to extract and analyze the original insect cuticles for other elements. Moreover, insect cuticles provide a more robust material for accurate radiocarbon dating.

In semiarid regions, time transgressive records are limited to high elevations, where lacustrine sediments are more reliably preserved over time. Guano deposits provide an attractive alternative for the development of palaeoenvironmental records at lower elevation sites. For example, in the Grand Canyon, variations in carbon and hydrogen isotope profiles of a bat guano profile indicate a change in monsoonal strength that closely follows climate in the North Atlantic (Fig. 2). $\mathrm{C}_{3}$ vegetation dominated during the globally cooler climates of the last glacial period, the Younger Dryas, and the 8.2-kyr (thousand-year) event, indicating more winter precipitation and/or cooler temperatures (Fig. 2). There was a slow increase after the Younger Dryas toward a stronger summer monsoon and a generally more arid and warmer climate.

Good depositional records are also rare in the tropics and are often biased toward perpetually wet swamps or areas close to river channels. In the nowwet tropical environment of Peninsular Malaysia, a bat guano deposit $\delta^{13} \mathrm{C}$ profile provides evidence of a much drier past, with open savannah present dur- 
4 Bat guano: Record of climate change

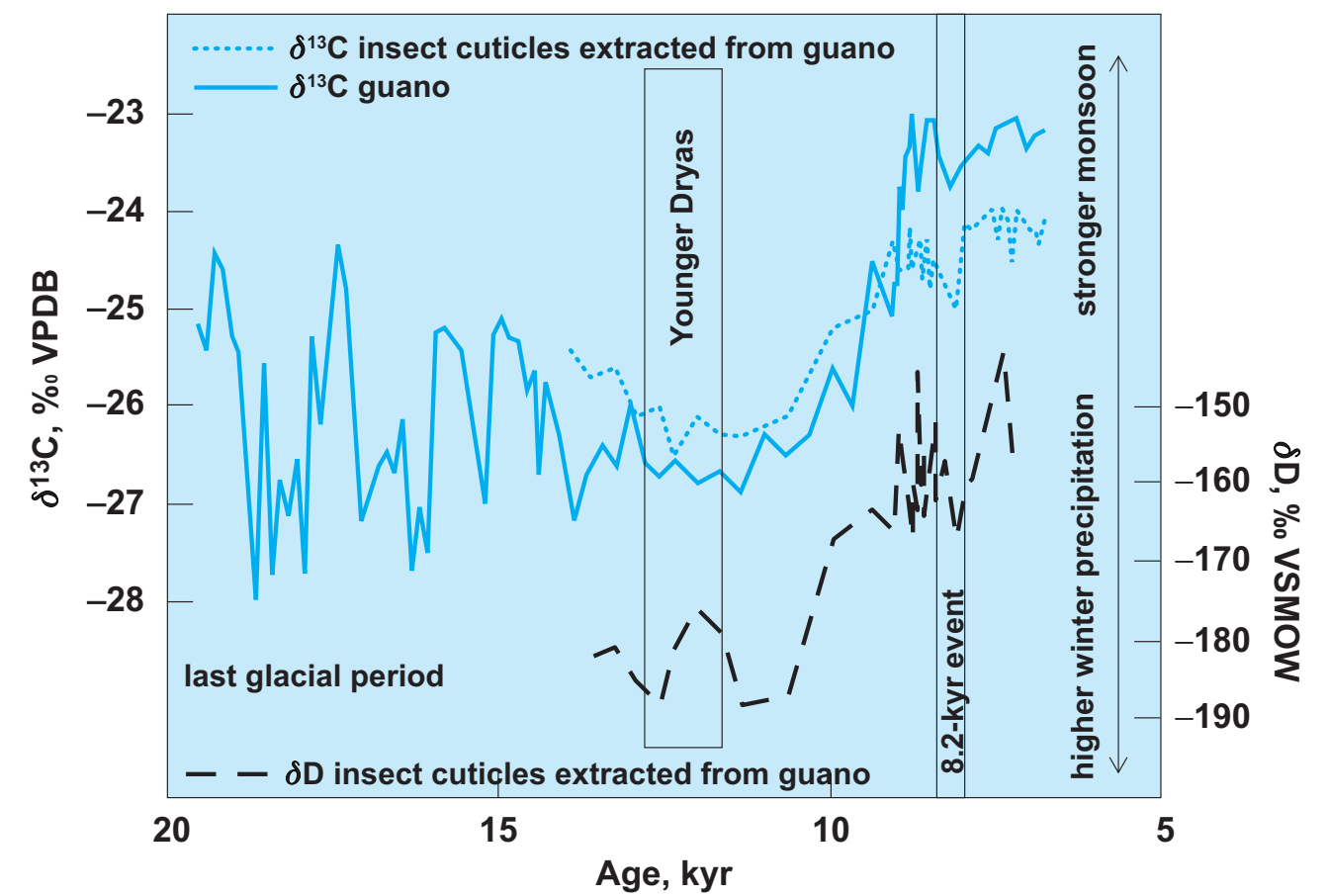

Fig. 2. Stable carbon and hydrogen isotope records from a Mexican free-tailed bat guano deposit from the Grand Canyon. Both records document a drastic change from a winter precipitation-driven climate to one characterized by the North American monsoon. sotope standards: Vienna Pee Dee Belemnite (VPDB) for reporting carbon stable isotope ratios and Vienna Standard Mean Ocean Water (VSMOW) for reporting stable hydrogen sotope ratios, both in \%o (parts per thousand).

ing the last glacial period (Fig. 3). Similarly, carbon isotopes in guano have been used to infer that parts of the Philippines that are now covered by tropical forest were covered by open savanna vegetation during the last ice age, implying lower and more seasonally distributed rainfall in the past. Such findings are unique and help to explain the trajectory of past environmental change in this globally significant "biodiversity hotspot" region. Moreover, understanding environments of insular Southeast Asia have significant implications for understanding early human dispersal in the region. Early humans arrived in the region 45,000-60,000 years ago, and may have encountered an inland coastal route similar to what they had previously experienced rather than dense tropical rainforest, as suggested by some models. Guano-derived records are now helping better define the environments of the past in this region and assist in developing a deeper understanding of the environmental drivers of human migration in prehistory.

Summary. This review has been concerned with variations of the stable isotope composition of guano as a paleoclimate record. We have briefly discussed how stable isotopes provide a robust archive of past climate and environment. However, it should be remembered that guano also contains several other proxy materials, such as pollen, charcoal, geochemical, and organic chemical proxies, which also archive environmental information. Reliable continuous records of past climate change from continental regions are harder to locate than in the marine environment. Particularly rare are well-dated tropical and semiarid records, with the majority of those 


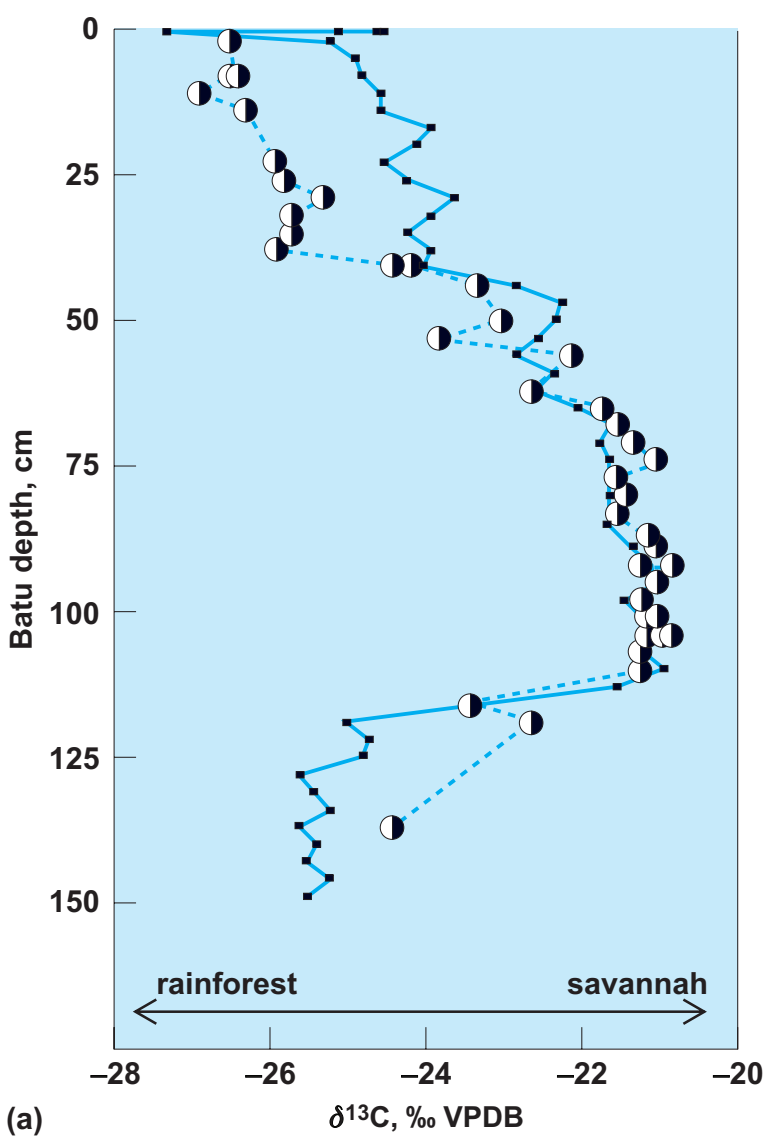

(a)

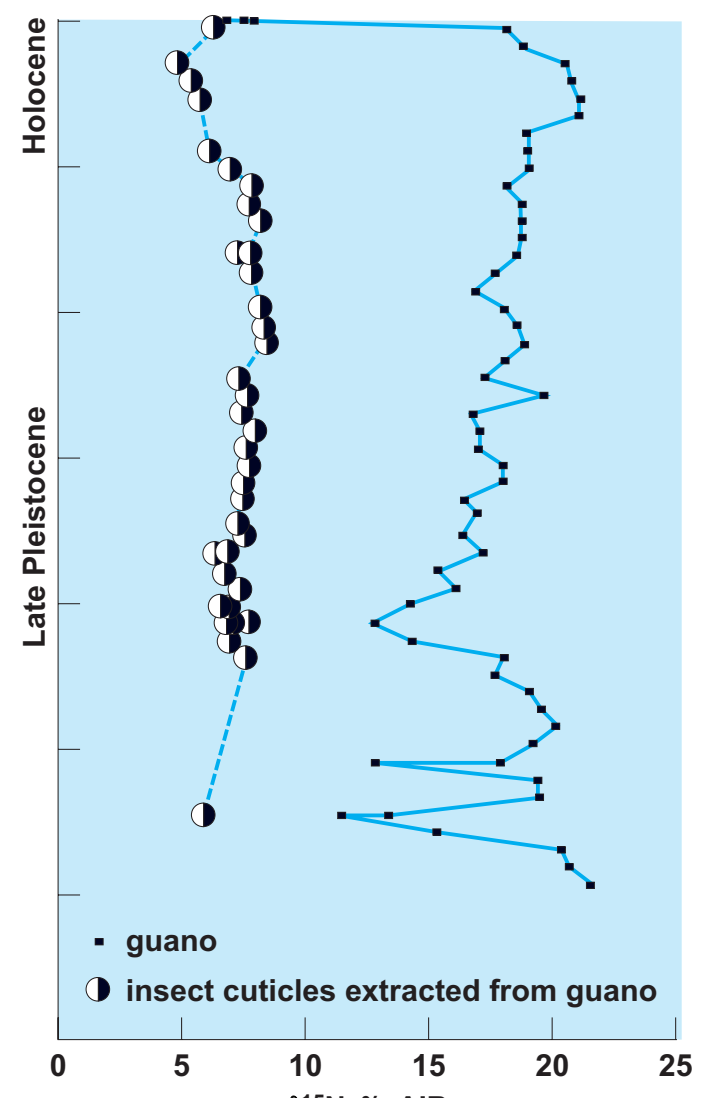

(b)

$\delta^{15} \mathrm{~N}, \%$ AIR

Fig. 3. A stable carbon and nitrogen isotope profile from Batu Caves near Kuala Lumpur, Malaysia. (a) High carbon isotope values during the last glacial period archive a savannah ecosystem during the Pleistocene that changed savane to the tropical rainost present values of extracted insect cuticles are much lower than nitrogen-bearing minerals in the bulk guano sediment and similar to those in standards. Vienna Pee Dee Belemnite (VPDB) for reporting carbon isotopes and atmospheric air (AIR) for reportin nitrogen isotopes, both in \%o (parts per thousand). 


\section{Bat guano: Record of climate change}

that exist coming from lacustrine environments and thus biased toward inherently wetter regions that may have had locally unrepresentative vegetation. Undoubtedly, guano records have their own biases, but it is only through comparing many proxies that we can accurately determine climates of the past.

For background information see CAVE; CHIROPTERA; CLIMATE HISTORY; CLIMATOLOGY; INSOLATION; ISOTOPE; MASS SPECTROMETRY; PALEOCLIMATOLOGY; PHOTOSYNTHESIS; RADIOCARBON DATING in the McGraw-Hill Encyclopedia of Science \& Technology.

Christopher Wursterl; Michael Bird; Donald McFarlane Key Words: arid; monsoon; paleoclimate; stable isotope; tropics

Bibliography. D. G. Constantine, Bats in relation to the health, welfare, and economy of man, in Biology of Bats, vol. 2, pp. 319-449, edited by W. A. Wimsatt, Academic Press, 1970; J. R. Ehleringer, T. E. Cerling, and B. R. Helliker, C4 photosynthesis, atmospheric $\mathrm{CO}_{2}$, and climate, Oecologia, 112(3):285299, 1997; D. R. Gröcke et al., Stable hydrogenisotope ratios in beetle chitin: Preliminary European data and re-interpretation of North American data, Quaternary Sci. Rev., 25(15-16):1850-1864, 2006; H. Mizutani, D. A. McFarlane, and Y. Kabaya, Carbon and nitrogen isotopic signatures of bat guanos as a record of past environments, J. Mass Spectrom. Soc. Jpn., 40(1):67-82, 1992; C. M. Wurster et al., Stable carbon and hydrogen isotopes from bat guano in the Grand Canyon, USA, reveals Younger Dryas and 8.2 ka events, Geology, 36(9):683-686, 2008.

Additional reading. M. I. Bird et al., A long record of environmental change from bat guano deposits in Makangit Cave, Palawan, Philippines, Earth Environ. Sci. Trans. Roy. Soc. Edinburgh, 98(1):59-69, 2007; M. I. Bird, D. Taylor, and C. Hunt, Palaeoenvironments of insular Southeast Asia during the Last Glacial Period: A savanna corridor in Sundaland? Quaternary Sci. Rev., 24(20-21):2228-2242, 2005; D. A. McFarlane, J. Lundberg, and A. G. Fincham, A late Quaternary paleoecological record from caves of southern Jamaica, West Indies, J. Cave Karst Studies, 64(2):117-125, 2002; R. F. Miller, P. Fritz, and A. V. Morgan, Climatic implications of $\mathrm{D} / \mathrm{H}$ ratios in beetle chitin, Palaeogeogr., Palaeoclimatol., Palaeoecol., 66(3-4):277288, 1988; C. M. Wurster, D. A. McFarlane, and M. I. Bird, Spatial and temporal expression of vegetation and atmospheric variability from stable carbon and nitrogen isotope analysis of bat guano in the southern United States, Geochim. Cosmochim. Acta, 71(13):3302-3310, 2007. 